\title{
APPLICATION AND EVALUATION OF THE ECOLOGICAL PSYCHOLOGY APPROACH TO INSTRUCTIONAL DESIGN (EPAID)
}

\author{
Judith Effken, Marylyn McEwen, Deborah Vincent, Kimberly Shea, Dianna Garcia-Smith, Youngmi Kang \\ College of Nursing, the University of Arizona, Tucson, AZ \\ Michael Young \\ Department of Educational Psychology, The University of Connecticut, Storrs, CT
}

\begin{abstract}
Teaching online can be particularly challenging when there is a need to immerse students located anywhere in the world in specific environmental contexts. We used the Ecological Psychology Approach to Instructional Design (EPAID) to design four courses in two concentration areas (Border Health, and Workforce and Healthcare Delivery Environments). In each case, we sought to provide students with a virtual first-hand understanding of contexts that they would not experience themselves. In this paper, we describe the major tenets of EPAID, the strategies we used to apply EPAID in the courses, and the results of our initial, formative evaluation.
\end{abstract}

\section{KEYWORDS}

Online Education; Instructional Design, Ecological Psychology, Instructional Theory, EPAID

\section{INTRODUCTION}

Teaching online can be particularly challenging when there is a need to immerse students located anywhere in the world in specific environmental contexts. At our university, doctoral students are required to take three or more courses that comprise a cognate (minor emphasis area) in support of their major research emphasis area. Based on student requests and contemporary healthcare issues, we designed two new cognates (Border Health, and Workforce and Health Delivery). In contrast to other cognates, these two options required students to become very familiar with the relevant environmental context (either the U.S. and Mexico border or acute care hospital management). However, only a few of our doctoral students enrolled in our Border Health course actually live in the U.S. Mexico border region-and not all students enrolled in our Workforce and Health Delivery course are actively involved in nursing management. In this paper, we describe how we used the Ecological Psychology Approach to Instructional Design (EPAID) to bring these two contexts to students and share the results of our preliminary evaluation.

\section{EPAID'S THEORETICAL FOUNDATIONS}

We adopted EPAID because it embeds learning in the complexity of real-life situations. EPAID is based on the ecological psychology of James J. Gibson [1, 2]. In a nutshell, Gibson's ecological psychology is a highly practical psychology of perception and action that focuses on how we get around in the world. It emphasizes the information that is available in the environment to support us in achieving our goals and the fit of the human to the environment. It also emphasizes the mutuality of perceiving and acting; that is, we perceive information in order to act in ways that achieve our goals; we also modify our actions in order to access available information. Thus, perception is not confined to the brain, but occurs in a brain in a head on a body that moves [3]. Goals are crucial to the perceiving-acting process because they set the boundaries on both the information that will be relevant and the actions that can be taken to realize the 
goals.

Given these views, it is not surprising that the ecological view of learning places more emphasis on what there is in the environment to be learned than other learning theories do. Learning emerges dynamically from learner-environment interactions in which the "whole-body" of the learner is embedded in the livedin world [4]. Learning is understood as an ongoing process of differentiation of available information that occurs through active exploration and selection of relevant information $[5,6]$. The ecological view of learning is similar to the notion of learners as "embodied and embedded" in everyday cognition [7] and is consistent with "situated cognition" and "situated action," in which each is embedded within the relevant context - and triggered by selection of a goal [4]. Goals, or intentions, are crucial because they define the aspects of the environment that are relevant. For that reason, helping students adopt appropriate learning goals is a critical component of EPAID.

Students come into our programs with career goals, but also with more immediate goals of passing a course, getting a paper written, or getting dinner on the table. These goals define what information students judge to be important - and how they select, from the available learning activities, those in which they will invest energy. Understanding how individual and group goals define how students approach learning requires explicit attention to course design. Designers must focus, not only on the individual student, but also on the student as part of a group and the shared goals that emerge within the group

\section{THE ECOLOGICAL PSYCHOLOGY APPROACH TO INSTRUCTIONAL DESIGN (EPAID)}

EPAID embeds learning in real-life situations [4, 8-10], which made it particularly appealing for our purposes. In its initial iterations, EPAID was used by John Bransford and his colleagues at Vanderbilt to improve mathematics and science education in the K-12 curriculum. For example, in the Jasper Woodbury series [11-13], students were presented with several different scenarios and required to use their knowledge of science and mathematics to help Jasper survive. In one vignette, Jasper purchases a new boat and now must decide whether he can safely get the boat home before dark or must stop for fuel and risk the fall of darkness. Students have to use several mathematical calculations that depend on speed, time, and fuel requirements to determine how to get Jasper home safely. Key data needed to solve problems are embedded in the scenarios. Examples and more details are available at: http://peabody.vanderbilt.edu/projects/funded/jasper/Jasperhome.html.

EPAID is similar to other learning theories in assuming that learners are self directed by their personal goals and that learning improves with practice and feedback, but it differs from other approaches because of its core tenets: a) Learning is the education of intention and attention, b) learning emerges within the interaction of student with course materials and c) learning and assessment should be situated in a rich, real-world context.

Educating intention requires helping students align their learning goals with those of the curriculum by engaging students through videos, stories of real-world problems that require curricular content to solve, thus inducing students to adopt goals for which the curriculum is relevant. Students can adopt new intentions as they work with others - or new intentions may emerge from their interaction in the learning environment [4]. "Ecological psychology describes the student as operating within an environmental niche co-created by the capabilities of the learner to act (effectivities) and properties of the physical and social environment that establish possibilities for action (affordances)" [14, p. 167]. In this view, knowledge is not simply for its own sake, but "for some purpose" that emerges from the coupling of student and learning environment. Any complete analysis of online learning "must acknowledge the complex nonlinear dynamics that unfold as an intentionally-driven learner interacts with a technologybased purposefully designed learning environment” [15, p. 48]. 
Application and Evaluation of the Ecological Psychology Approach to Instructional Design (EPAID)

Educating attention means helping students learn to detect aspects of their environments that have functional value by presenting exemplars through which they can "tune" their detection skills. This attunement can develop vicariously through the scaffolding that occurs when students work with more experienced peers in a shared environment $[9,16]$. Elsewhere we have referred to this attunement process as the biasing of an otherwise random walk process [8]. When learning begins, "diffuse control" predominates because students have not yet learned to differentiate the relevant from the irrelevant information so they weigh all data equally and sample the available information sources quite randomly. As learning continues, students begin to differentiate useful from not-so-useful information and actions, and become more likely to pursue information and actions that move them toward their goals. Their better-differentiated perception skills constrain the actions they take, which in turn constrain the information they detect. To facilitate this "biasing" process, however, the instructional environment needs to be designed to highlight important distinctions and provide timely feedback that helps students differentiate from course materials what is most important and goal-relevant. Sometimes facilitating this differentiation process using contrived problems may require that instructors also devise "red herrings" (information that is not relevant to the problem); however, when the problems are more reality based, the "red herrings" occur naturally.

Learning emerges from the interaction of learner and instructional environment. The ideal assessment system would provide both student and instructor with real-time information about students' progress, identify potential problem areas and perhaps even suggest interventions so that the instructor can provide appropriate scaffolding initially and remove it as the student progresses. With more and more learning provided asynchronously online, building some of the assessment expertise into the interface would be ideal so that "just-in-time" feedback can be provided effectively. Because so much learning occurs invisibly in students' heads, we continue to be challenged to make this "off-line” learning more transparent to instructors without being overly intrusive [16].

\section{APPLYING EPAID TENETS TO COURSE DESIGN: THE FACULTY PERSPECTIVE}

With external funding from the U.S. Department of Health and Human Services (HRSA), our team used EPAID to develop four courses as part of two minor cognates for our online nursing doctoral program. Because the courses were implemented sequentially, we were able to apply what we learned while developing the initial courses to those implemented later. Over the two-year development and implementation period, the team included six faculty, four teaching assistants, an instructional designer, programmers, media experts, illustrators, and a librarian.

\section{A. A Brief Overview of the Courses}

The goal of the Border Health course was to help students develop a deep understanding of U.S. and Mexico border health issues. The course focused on increasing students' knowledge of border health systems, binational collaboration, policy and research so that students could help shape culturally competent research programs that respond to the complex issues influencing border health and border health care systems. Learning activities were organized into four modules, each extending over a 3 to 5 week period. Students demonstrated integration and synthesis of their new knowledge through a challenge posed at the end of each module. The challenges required students to analyze and synthesize the complex issues influencing border health and border health care systems in order to design a nursing research agenda for U.S. and Mexico border health.

The goal of the Technology for Expanding Healthcare Capacity course (hereafter referred to as the Technology course) was to help students learn to design and apply information technology to a specific clinical population (individuals with Diabetes) in a particular context (the U.S. and Mexico Border). The 
course was part of the Border Health minor cognate, but was implemented first so that much of the contextual information that would ultimately be part of the Border Health course was included. The course was organized into 5 modules, each one culminating in a specific challenge.

The goal of the Workforce and Healthcare Delivery Environment course (hereafter referred to as the Workforce course) was to help students critically analyze contemporary research about the impact of the nursing workforce and healthcare delivery environments on quality and cost outcomes. To accomplish this in a 5-week intensive summer course, the course was organized into two modules, with one real-life challenge posed in each module.

The Translational Research course was the last of the four courses to be implemented and was part of the Workforce minor cognate. This course was designed to help students understand the meaning of translational research and the models and methods associated with translating evidence into a variety of healthcare settings. Unlike the previous courses, this course was organized into five modules with a challenge associated with the first, third, and fifth modules. In the second and fourth modules discussions were used to assist students to synthesize previous content and prepare for the next challenge.

In the following sections, we describe how we applied EPAID's core tenets, providing specific examples from the various courses.

\section{B. Immersing Students in Rich Environments}

The four courses utilized different strategies to immerse students in rich learning experiences that create a virtual sense of place. In the Border Health course, we wanted students to experience life in the U.S. and Mexico Border region without being physically present at the border. To accomplish this, we created a collage of film, poetry, music, and text. As students explored the evidence on health outcomes on both sides of the border in four sister cities, they experienced first-hand the challenges imposed on providers, patients, and the healthcare system by two languages, two cultures, and frequently opposing governmental policies.

In the Workforce course, students were invited to serve as consultants to a Clinical Nurse Executive (CNE). The CNE asked the consultants for a research-based plan to improve the hospitals' quality outcomes without incurring too much cost. Narrated illustrations depicted the CNE welcoming the students, showing them around the hospital, giving them key information about her problem, and then asking them for help. Students had to discern, from the information she provided, what was most relevant and important.

In the Technology course, we used "Infographics" (Fig. 1) to establish a rich set of factors that students might need to consider related to each challenge they were given. Because the central challenge of the course was to explore the state of the science of informatics and determine what information technology might improve health outcomes for Diabetics individuals with diabetes in the U.S. and Mexico Border region, an array of resources was pulled together in the infographic. Students clicked on each object to explore materials. Students were expected to investigate widely, but were not required to explore each and every available resource. 


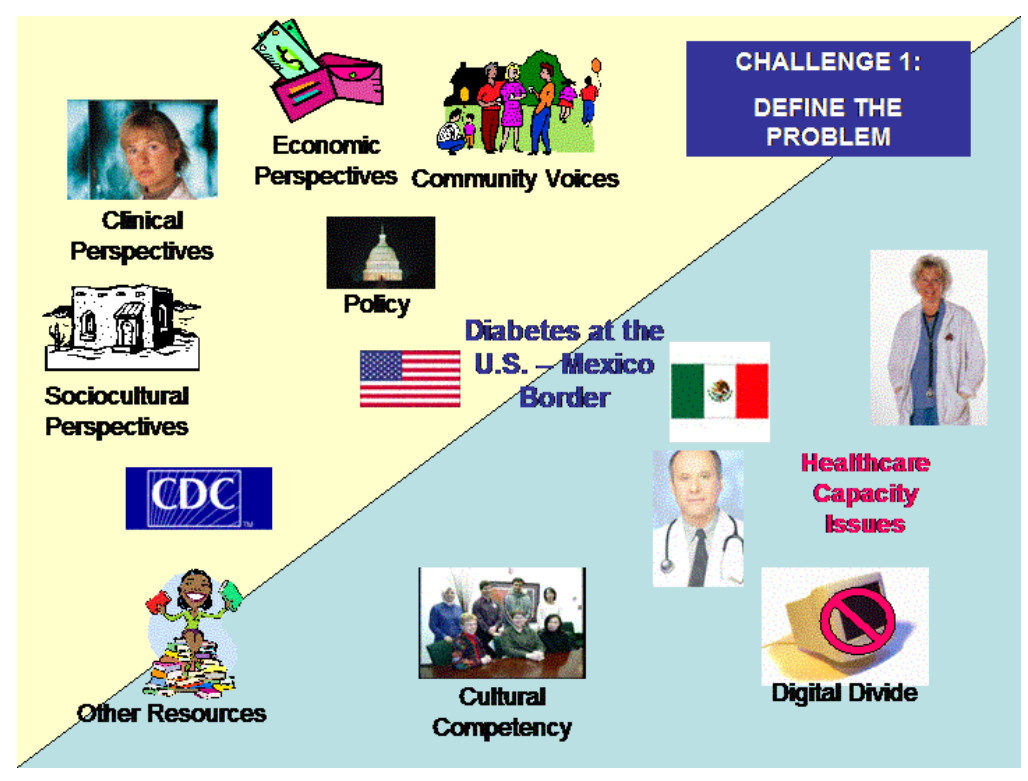

Figure 1. Infographic Integrating Content for Challenge 1

\section{Educating Intention}

In addition to outlining course goals in syllabi and videotaping faculty course introductions, all courses incorporated a course map (Fig. 2). In some courses, the course map served as an additional guide to the course for students; but in the Technology and the Translational Research Courses, the course map was also the main navigational tool. Clicking on a node in the course map for those courses took students to the instructions and resources to accomplish the particular challenge for that module.

At the beginning of each class, we asked students to post a brief self introduction. We also asked them to tell us what they hoped to gain from each class and how they anticipated that they would use the knowledge in their future research.

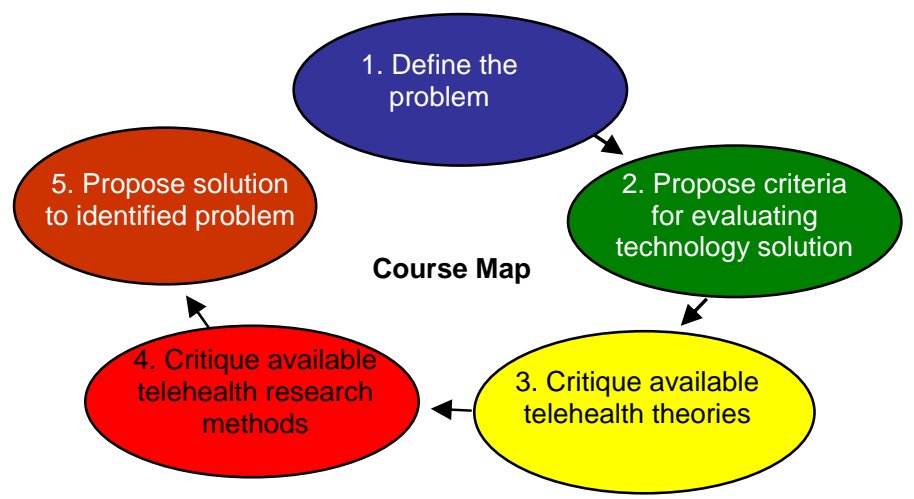

Figure 2. Interactive Course Map

\section{The Border Health Exemplar}

In the Border Health course, in addition to the introduction described above, we also asked students which borders were most relevant to them and their future research. Defining this explicitly helped them compare and contrast their own experience with the U.S. and Mexico Border exemplar that was used 
throughout the course. We sought to educate students' intentions further through an elaborate process of cultural immersion via multimedia. For example, students were asked to critique Gloria Anzaldúa's poem, "To Live in the Borderlands Means You” [17, pp. 91-92]. Students also viewed PBS video clips that captured different dimensions of border life through interviews of persons living in the border region.

The students' asynchronous discussion postings demonstrated that they were making new discoveries about the border region. Students soon hypothesized that the geographic diversity they observed in the 2,000 miles of U.S. and Mexico border that stretches from California to Texas might impose very different issues in each of the border communities. Students also began to recognize how the diverse mechanisms now used for border control (e.g., walls in Arizona, the Rio Grande River in Texas, and the ocean and metal wall separating San Diego from Tijuana) disrupted and separated families living along the border. By the end of the first week, students' postings documented their rapid cultural immersion into the historical, socio-political, cultural and economic issues of the U.S. and Mexico border region. One student commented: "I feel I have had a crash course in border health already in just one week."

As the course progressed, students' postings told us that they were beginning to recognize the loss and confusion of cultural and national identity, forced assimilation, oppression, and the tension that underpins cultural duality. Some postings reflected students' personal experiences of being a minority in a majority world as they compared and contrasted U.S. and Mexico border issues with those of other borders (e.g., the U.S. - Canadian border).

In Challenge I, students were informed that the U.S. and Mexico Border Health Commission requested that they conduct a focused assessment of two U.S. border counties-one in Arizona adjacent to the Mexican state of Sonora, and the other in Texas adjacent to the Mexican state of Chihuahua. Student teams were given two weeks to obtain a variety of data describing the U.S. counties and adjacent Mexican counties. Links to several data-rich websites were provided in the syllabus to facilitate student research. In addition, the librarian from the Arizona Hispanic Center of Excellence was available as a consultant. Each team reported their findings in an executive summary. Reviewing and discussing the reports enabled students to compare and contrast four U.S. and Mexico border communities, identify shared and unique border issues, and begin to generate potential solutions for complex binational health issues.

\section{The Technology Exemplar}

In this course, students were asked to design an information technology solution that could enhance care to the diabetic population at the U.S. and Mexico border. This required that they explore, not only the context for the problem (i.e., border and cultural issues), but also available research on technology solutions. Because students came into the course with a variety of backgrounds (some clinically focused; others informatics majors), we asked them to share their expertise. An interactive course map was developed to guide students through the course. Clicking on one of the modules in the course map defined each module and associated challenge then took students to the relevant infographic that brought together the specific resources for that module.

\section{The Workforce Exemplar}

In the Workforce course, we educated students' intentions by immersing them in both the science and the lived experience of workforce shortages and turbulent working conditions. We framed the course around an ongoing scenario in which students were engaged as consultants to a Chief Nursing Executive (CNE) at a fictitious hospital. Students were asked to develop a research-based plan to help the CNE solve staffing and quality of care issues. Before beginning the challenges, students reviewed current issues and trends in health care that had particular relevance to analyzing workforce and working condition concepts and interventions. To help them transition from the literature to the challenges, we asked students to

develop a concept map based on their analysis of key constructs and concepts, the relationships among 
Application and Evaluation of the Ecological Psychology Approach to Instructional Design (EPAID)

them, and their relationships to relevant outcomes, including staff satisfaction, retention, and patient safety and quality. The lively class discussion of each student's concept map helped students focus on salient concepts and issues.

\section{The Translational Research Exemplar}

In the Translational Research course we asked students to design a template for conducting translational research regardless of setting or specific problem. To do this, students needed to immerse themselves in the literature to develop a definition of translational research and a protocol for assessing when evidence is ready to be translated into clinical practice. Many of the lessons we learned in developing previous courses were incorporated into this course. As in the technology course, students in this course had a variety of clinical and research experience and so were asked to share their expertise; and an interactive course map was developed to guide students through the course. In addition to the literature, we were able to include videos of a conference on translational research, and podcast interviews with leaders in the field.

\section{Educating Attention}

We educated students' attentions through team assignments structured as real-world challenges. In general, students were asked to respond briefly to an initial question challenge posed by the instructorwithout doing any research, although they could skim course materials if they wished. This allowed the class to identify various perspectives and expertise in the class that they might utilize later. Students were then expected to work in their assigned dyads (teams of two) to explore course materials in more detail and post an initial response to the challenge, and then respond to responses of others dyads. With this additional feedback from peers and faculty, students then honed their final response, which was posted in the group discussion and graded by the instructor.

\section{The Border Health Exemplar}

In the Border Health course, for two of the four challenges, students were divided into teams based on their previous experience and expertise with Spanish language, Mexican culture, and international borders to increase the likelihood that they would be "attuned" to, and therefore act on, the same information [4]. Combining students with Spanish language skills with students who had experience in interpreting population-level data sets facilitated detection of the information relevant to the community assessment challenge. Team discussions, sharing of work documents, and review of draft papers occurred in separate discussion forums. Faculty helped student teams differentiate goal-relevant resources as they monitored and participated in the discussions.

\section{The Workforce Exemplar}

In the Workforce course, to engage students, we created narrated illustrations in which a nurse executive discussed the problems facing her hospital and her own goals for addressing staffing shortages and improving quality of care. In the first scenario, students were presented with a wealth of detail about the hospital and the CNE's goals. Although much of the material was useful background information, not all of it was needed to develop a plan to improve quality of care. Students were required to differentiate relevant material from irrelevant material. Students became very engaged, to the point of creating fictitious names for their consulting firms.

In addition, the challenges required that students provide documentation to support their recommendations for both academic and administrative audiences. In the paper for the academic audience, students were expected to synthesize and integrate extant literature to support their assertions. For the administrative audience, students prepared an executive summary in which they presented their major findings, recommendations for implementing change, and their rationale for each recommendation. This forced the students to consider how the same information could be presented in ways that would be 
meaningful to different groups, yet another way to educate attention. Dyad discussions, sharing of documents and drafts occurred in separate electronic forums. Because this was a small class, some wholeclass discussions took place in real-time using Breeze. Each dyad presented their recommendations to the class using narrated Power Point presentations then answered questions during the real-time discussion period.

\section{E. Lessons Learned}

Applying EPAID's tenets required that we explore a variety of strategies to educate students' intentions and attentions. Our consultant, Michael Young, both educated us and challenged us to explore, not only the affordances of a new learning theory, but also the advantages of new instructional strategies. Our instructional designer helped us actualize both the theory and strategies.

Selecting and integrating the rich materials into the course was time consuming. In addition, we found that too much richness can be overwhelming for students, so we subsequently cut back on some of the course materials. The Technology course used an interactive course map that was 3-4 layers deep, depending on the module, and presented materials linked to topics, rather than sequentially. Some students loved the novelty of the approach, but a few found this difficult to track, so later courses added an alternative sequential approach to listing course resources to meet both groups' preferences.

With each of the four courses, we experienced dyad issues that are consistent with face-to-face group dynamics. In some cases, students who were assigned to work together had done so unsuccessfully in another course and brought that negative experience with them. In other cases, the students had very different work habits, which made it difficult for them to work together. In one case, the students were so committed to their own goals that they could not agree on a final response to the challenge-and the instructor finally let them provide individual responses.

Still, we found this to be a particularly rewarding teaching experience and were delighted to see students so engaged in real-world problems. Working as a team on courses implemented over 4 semesters allowed us to learn from each other. In group meetings, we supported each other by brainstorming and sharing ideas that would keep us true to EPAID principles. When something worked well (e.g., when one student commented that “This is what an online course should be like!”) we celebrated; when it didn't (e.g., when teams could not work effectively together) we developed new strategies. In the following section, we report the results of a preliminary, formative evaluation of the outcomes.

\section{FORMATIVE EVALUATION}

As online learning has entered the mainstream of higher education, it has raised issues of quality [18], online teaching methods [19], and course design and delivery [20]. Consequently, there is a growing nationwide need for credible quality assurance in online learning [21]. Practical issues of increasing demand, sustaining cost-recovery, and meeting accreditation requirements have also driven the need for online course quality assurance methods that utilize different evaluation tools than those used in traditional face-to-face courses. We report here on three different formative evaluations we conducted. The first explored the degree to which our course designs incorporated national standards. The second evaluated the degree to which we had incorporated EPAID's tenets. The third assessed students' reactions to the courses.

\section{A. Did the courses meet national standards?}

\section{Method}

As one of their teaching assignments for the project, two graduate teaching associates were asked to conduct a preliminary evaluation of the courses. Neither had participated in the design of the courses nor 
Application and Evaluation of the Ecological Psychology Approach to Instructional Design (EPAID)

taken the courses. Both reviewers had prior experience as nurse educators in face-to-face courses, and one had taught courses online for three years.

After conducting a literature review of available evaluation tools, the teaching associates adopted the Quality Matters (QM) Evaluation Rubric (http://www.qualitymatters.org/). The QM Rubric includes eight categories of standards with several standards within each category. We did not include the last two categories (Learner Support and Accessibility) because, in our program, these are addressed at the College/University level rather than at the course level. This left us with the following categories (number of standards for each category is shown in parentheses): Course Overview (6), Learning Objectives (5), Assessment \& Measurement (5), Resources \& Materials (5), Learner Interaction (5), and Course Technology (6). Although the QM Rubric does not assume that each standard must be met to have a quality course, for the purpose of this preliminary evaluation, we assumed that higher scores correlated with higher quality and adopted a binary choice metric $(1=$ present, $0=$ absent $)$. The resulting scale had a possible total of 32 points.

The reviewers initially explored the course materials as if they were actually taking the courses, and then rated each course using the QM Rubric. Independent reviews were conducted by each teaching associate and the results of the reviews were compared. When differences could not be resolved through consensus, the mean score was reported.

\section{Results}

Results of the evaluation are summarized in Table 1 (note that the number of possible points in each standard varied). All courses received maximum points for Course Technology and scored nearly as high on Resources and Materials. Two courses (Workforce and Technology) were rated relatively low on Course Overview; but all four courses had room to improve in this area. All courses also had room for improvement in the area of Assessment.

\begin{tabular}{llllll}
\hline Standard & $\begin{array}{l}\text { Possible } \\
\text { Points }\end{array}$ & Course & & & \\
\hline & & Workforce & Technology & Border Health & Translation \\
\hline Course Overview & 6 & 2.5 & 2.5 & 4.0 & 4.0 \\
\hline Learning Objectives & 5 & 4.5 & 5.0 & 3.5 & 4.0 \\
\hline $\begin{array}{l}\text { Assessment } \\
\text { Measurement }\end{array}$ & 5 & 3.0 & 5.0 & 3.5 & 4.5 \\
\hline Resources \& Materials & 5 & 5.0 & 5.0 & 4.5 & 5.0 \\
\hline Learner Interaction & 5 & 4.5 & 4.0 & 4.0 & 4.0 \\
\hline Course Technology & 6 & 6.0 & 6.0 & 6.0 & 6.0 \\
\hline Total & 32 & 25.5 & 27.5 & 25.5 & 27.5 \\
\hline
\end{tabular}

Reviewers felt that the course maps were useful for helping students better understand course goals and structure. Reviewers also highlighted the many learning opportunities and the challenging, but rich learning environments that facilitated students' interaction. Reviewers felt that the real world challenges around which the four courses were organized provided numerous opportunities for students to interact with each other and with faculty, as well as with the content. Reviewers noted that the Border Health course was particularly effective at integrating guest lecturers, websites, videos and readings. Reviewers commented on the visually creative design of the Technology course. For some courses, reviewers were concerned that the amount of content and resources provided might be overwhelming for students. Reviewers suggested adding site navigation instructions to all courses, even in the Technology course, 
where an online tutorial helped students to effectively navigate the interactive course map. Reviewers also recommended adding grading rubrics in some areas, for example, discussion.

Reviewers reported that the courses, which creatively focused on situating the learner within real-life environments, easily met QM standards for Learner Interaction, Resources \& Materials and Course Technology. Generally courses met the standards for Learning Objectives, but reviewers suggested that providing more objectives at the module/unit level might facilitate better education of students' intentions. The evaluation suggested that faculty pay additional attention to developing assessment strategies that would make grading policies more transparent and easier for students to understand. Finally, additional navigation instructions and instructor information were suggested for all courses at the beginning of the course.

\section{B. Mapping QM Standards to EPAID Tenets}

\section{Methods}

To see whether the QM Standards also could be used to evaluate how well the courses met EPAID principles, four faculty and three graduate students together mapped individual QM standards onto EPAID tenets. Ultimately, the group agreed that 19 of the 32 QM standards within the six categories used for the first evaluation could be mapped onto EPAID tenets (Table 2).

\begin{tabular}{|c|c|c|c|c|}
\hline QM Standards & EI & EA & EL & SA \\
\hline \multicolumn{5}{|l|}{ I. $\quad$ Course Overview \& Introduction } \\
\hline $\begin{array}{l}\text { 1.1 Navigational instructions make the organization of the course easy to } \\
\text { understand. }\end{array}$ & $\mathrm{x}$ & & & \\
\hline $\begin{array}{l}1.2 \text { A statement introduces the student to the course and to the structure } \\
\text { of the student learning. }\end{array}$ & $\mathrm{x}$ & & & \\
\hline \multicolumn{5}{|l|}{ II. Learning Objectives } \\
\hline $\begin{array}{l}2.1 \text { The learning objectives of the course describe outcomes that are } \\
\text { measurable. }\end{array}$ & $\mathrm{x}$ & & \multirow{5}{*}{$\mathrm{x}$} & \\
\hline $\begin{array}{l}2.2 \text { The learning objectives address content mastery, critical thinking } \\
\text { skills, and core learning skills. }\end{array}$ & & & & \\
\hline $\begin{array}{l}2.3 \text { The learning objectives of the course are clearly stated and } \\
\text { understandable to the student. }\end{array}$ & $\mathrm{X}$ & & & \\
\hline $\begin{array}{l}2.4 \text { Instructions to students on how to meet the learning objectives are } \\
\text { adequate and easy to understand. }\end{array}$ & $\mathrm{x}$ & & & \\
\hline $\begin{array}{l}2.5 \text { The learning objectives of the course are articulated and specified on } \\
\text { the module/unit level. }\end{array}$ & $\mathrm{x}$ & & & \\
\hline \multicolumn{5}{|l|}{ III. Assessment \& Measurement } \\
\hline $\begin{array}{l}\text { 3.1 The types of assessments selected measure the stated learning } \\
\text { objectives and are consistent with course activities and resources. }\end{array}$ & \multirow[t]{4}{*}{$\mathrm{x}$} & & & $\mathrm{X}$ \\
\hline $\begin{array}{l}3.3 \text { Assessment and measurement strategies provide feedback to the } \\
\text { student. }\end{array}$ & & & & $\mathrm{x}$ \\
\hline $\begin{array}{l}\text { 3.4 The types of assessments selected and the methods used for } \\
\text { submitting assessments are appropriate to the distance learning } \\
\text { environment. }\end{array}$ & & & & $\mathrm{x}$ \\
\hline $\begin{array}{l}3.5 \text { "Self-check" or practice types of assignments are provided for quick } \\
\text { student feedback. }\end{array}$ & & & & $\mathrm{x}$ \\
\hline IV. Resources \& Materials & & & & \\
\hline $\begin{array}{l}\text { 4.1 The instructional materials have sufficient breadth, depth, and } \\
\text { currency for the student to learn the subject. }\end{array}$ & $\mathrm{X}$ & 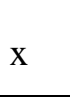 & & \\
\hline
\end{tabular}


V. Learner Interaction

5.1 The learning activities promote the achievement of stated learning objectives and learning outcomes.

$\mathrm{X}$

5.2 Learning activities foster instructor-student, content-student, and if appropriate to this course, student-student interaction.

5.5 The course design prompts the instructor to be active and engaged with the students.

VI. Course Technology

6.1 The tools and media support the learning objectives of the course and are integrated with texts and lesson assignment.

6.2 The tools and media enhance student interactivity and guide the student to become a more active learner.

\section{Table 2. QM Standards by Applicable EPAID Tenets}

(EI=educating intention, EA=educating attention, EL=emergent learning, SA=situated assessment) We then used the mapped standards to evaluate the degree to which we had met specific EPAID tenets. Course evaluation summaries were adapted to include only the standards that were mapped to the EPAID tenets listed in Table 2. The mean scores for each EPAID tenet for all four courses were calculated. A total course mean score was calculated by averaging the two reviewers' scores.

\section{Results}

Results are summarized in Table 3. Overall, compliance with EPAID tenets was quite high. All courses received maximum points for Emergent Learning and Educating Attention and scored nearly as high on Situated Assessment. Two courses (Workforce and Border Health) had room to improve in Educating Intention.

\begin{tabular}{llllll}
\hline Standard & $\begin{array}{l}\text { Possible } \\
\text { Points }\end{array}$ & Course & & & \\
\hline & & Workforce & Technology & Border Health & Translation \\
\hline Educating Intention & 8 & 6.5 & 7.5 & 5.5 & 7 \\
\hline Educating Attention & 2 & 2 & 2 & 2 & 2 \\
\hline Emergent Learning & 5 & 5 & 5 & 5 & 5 \\
\hline Situated Assessment & 4 & 3 & 4 & 3 & 4 \\
\hline Total & 19 & 16.5 & 18.5 & 15.5 & 18 \\
\hline
\end{tabular}

Table 3. EPAID Evaluation Results Summarized by EPAID Tenet and Course

In sum, our review found that the four courses fully met the seven QM standards corresponding to Educating Attention and Emergent Learning and Situated Assessment. Generally courses also met the QM standards relating to Educating Intention and Situated Assessment; although, as previously noted, providing more objectives at the module/unit level might facilitate better education of students' intentions.

\section{The Student Perspective \\ 1. Methods}

After obtaining approval from the University's institutional ethics review board, we conducted a survey of students who had participated in one or more of the courses. We designed a 10-item questionnaire that focused on evaluating how well the course goals matched the learner's own goals, to what degree the course facilitated the students' adoption of the course goals, navigation within the instructional environment, creation of a shared environment with other students, and perceptions of how the course fit 
into the students' world. Items 1-4 used a 5-point Likert response scale ranging from "strongly agree" to "strongly disagree." Respondents were also asked to rate the feedback from faculty, other students, and course assignments using three different descriptors for each item (e.g., highly stimulating to highly boring, highly useful to highly useless, and almost always helpful to almost never helpful). Respondents also chose five descriptors that they felt best described the course from the following list: difficult, integrative, meaningful, routine, applicable, too much, confusing, stimulating, constraining, challenging, frustrating, fragmented, boring, clear, broadening, not enough, simplistic, meaningless, not applicable or innovative. Finally, the questionnaire included three open-ended questions about aligning their own goals with course goals, differences in these courses from other courses taken, and navigation issues. Respondents completed the questionnaire online. A computer program automatically compiled responses into a de-identified excel spreadsheet for analysis.

\section{Results}

Twenty-seven students had taken one or more of the classes. Twenty questionnaires were completed (a $74 \%$ response rate). The results for the first four questions are summarized in Table 4.

\begin{tabular}{|c|c|c|}
\hline Questions/Courses & Range & $\begin{array}{c}\text { Mean (Standard } \\
\text { Deviation) }\end{array}$ \\
\hline \multicolumn{3}{|c|}{ 1. The way the course was designed helped me to achieve my own goal(s) for the course. } \\
\hline Workforce $(n=4)$ & $4-5$ & $4.75(0.50)$ \\
\hline Technology $(n=7)$ & $2-5$ & $4.00(0.58)$ \\
\hline Border Health $(n=6)$ & $1-5$ & $3.67(0.82)$ \\
\hline \multirow[t]{2}{*}{ Translational Research $(n=3)$} & $4-5$ & $4.67(0.58)$ \\
\hline & Mean & $4.27(0.62)$ \\
\hline \multicolumn{3}{|c|}{ 2. By the end of this course, my goals had become more congruent with the stated course goals. } \\
\hline Workforce $(n=4)$ & $4-5$ & $4.50(1.16)$ \\
\hline Technology $(n=7)$ & $2-5$ & $4.00(1.29)$ \\
\hline Border Health $(n=6)$ & $1-5$ & $3.50(1.00)$ \\
\hline \multirow[t]{2}{*}{ Translational Research $(n=3)$} & $5-5$ & $5.00(1.46)$ \\
\hline & Mean & $4.25(1.23)$ \\
\hline \multicolumn{3}{|l|}{ 3. Navigation within the course was intuitive. } \\
\hline Workforce $(n=4)$ & $3-5$ & $4.00(1.75)$ \\
\hline Technology $(n=7)$ & $2-5$ & $4.00(1.98)$ \\
\hline Border Health $(n=6)$ & $1-5$ & $3.33(1.37)$ \\
\hline \multirow[t]{2}{*}{ Translational Research $(n=3)$} & $4-5$ & $4.67(1.52)$ \\
\hline & Mean & $4.00(0.17)$ \\
\hline \multicolumn{3}{|c|}{ 4. I wish other instructors would use this type of course design. } \\
\hline Workforce $(n=4)$ & $3-4$ & $3.50(.58)$ \\
\hline Technology $(n=7)$ & $1-5$ & $3.86(.00)$ \\
\hline Border Health $(n=6)$ & $1-5$ & $3.50(.58)$ \\
\hline \multirow[t]{3}{*}{ Translational Research $(n=3)$} & $4-5$ & $4.33(.58)$ \\
\hline & Mean & $3.80(.43)$ \\
\hline & Overall Mean & $4.08(.98)$ \\
\hline
\end{tabular}

Table 4. Student Questionnaire Responses to Questions 1-4

The last course that applied EPAID, Translational Research, had the highest survey ratings, probably benefiting from lessons learned in the development of earlier courses, although we cannot rule out that students who had experienced other EPAID courses and liked them chose this course as well. In the Border Health course, a number of students voiced their frustration with the Spanish-language links and readings - even though each dyad included a Spanish-speaking student. In a sense, these students simply 
Application and Evaluation of the Ecological Psychology Approach to Instructional Design (EPAID)

were experiencing the reality of the border setting in which English or Spanish-speaking individuals must struggle to access information in another language; but they had not anticipated this additional challenge and apparently were uncomfortable with depending on their peer for this information. Some students were Puerto Rican; we did not anticipate the degree to which cultural differences with Mexico would be problematic. Ultimately, the class split into two camps, never aligning around a single set of goals. Most respondents (85\%) rated feedback from other students as somewhat or highly useful; $70 \%$ found it somewhat or highly stimulating; and 55\% reported that it was often or almost always helpful. Most (85\%) students rated course assignments as somewhat or highly stimulating; $90 \%$ found them somewhat or highly useful; and 60\% rated assignments as somewhat or highly difficult.

The most frequently used descriptors for the enhanced courses were integrative (65\%), challenging (60\%), applicable (50\%), stimulating (55\%) and innovative (55\%). Nearly all respondents (95\%) reported that their own learning goals were consistent with at least one of the goals posted by the instructor in the course syllabus. Even though the evaluation survey was completed by students up to $1 \frac{1 / 2}{2}$ years after taking the courses, most respondents (85\%) identified differences in these courses from others they had taken that were consistent with one of EPAID's goals. Half the respondents who described the group work viewed it as problematic. Most respondents (80\%) reported no navigation problems, but noted that it "took a while" to learn.

\section{CONCLUSION}

EPAID, which incorporates a range of contemporary pedagogy, provides a parsimonious framework for addressing student online work as richly embodied and embedded perception and action. Applying the theoretical underpinnings of EPAID for course development required a shift in the way we taught. In some ways, EPAID is similar to other constructivist instructional theories (e.g., problem-based learning or anchored instruction) that treat learning as an active process that should take place in authentic contexts. However, it differs in several important ways: First, EPAID views learning as a matter of differentiating available, complex environmental information, rather than constructing it from smaller bits and pieces. Second, the focus of our instructional strategies were on educating students' intentions (goals) so that they aligned with those of the course and then helping them learn to detect relevant from irrelevant information (educating their attentions). Third, we sought to help students exploit, not only their own backgrounds, but also the various effectivities (capabilities, as well as prior knowledge and experience) of their peers to help them learn to detect the affordances of the materials needed for the challenges. Finally, we attempted to situate assessment within the context of the course, specifically within the challenges posed.

Our approach to instructional design is also consistent, albeit not intentionally so, with Garrison's Communities of Inquiry model [22] because of the attention we paid to teaching presence (aligning goals, educating attention, and timely, ongoing feedback), social presence (dyads, group discussions-both asynchronous and synchronous) and cognitive presence (the emphasis on engaging students in complex, real-world challenges).

We were fortunate that the development and implementation of the online courses were supported by a HRSA grant. This meant that we had resources to invite consultants with expertise in EPAID and to explore alternative online delivery formats. Our faculty team met bi-monthly during the development and implementation of the courses. We met with consultants either in face-to-face or virtual work groups. This supportive network was essential for stimulating ideas, as well as assuring that we remained true to the philosophical and theoretical underpinnings of EPAID. In addition, the meetings and workshops provided a forum in which faculty was able to share teaching strategies, resources, frustrations and accomplishments.

Designing these courses using EPAID has been exciting, renewing, and satisfying for faculty. Using 
EPAID, we successfully aligned students' objectives with those of the course. In very rich contexts, the instructional strategies used to embed the challenges helped students identify what was most important. The intense group work with multiple opportunities for feedback and course correction helped focus students' attention on the most meaningful and relevant materials, given the goal. It was clear to faculty and students alike that considerable learning emerged; that is, there were many "aha" moments throughout the course, and the final submissions demonstrated higher levels of analysis, integration, and synthesis than initial postings. Situated assessment occurred as faculty followed the progress of groups and intervened if the group was getting off target. In addition, videoconferences provided yet another way for faculty to assess students' understanding of key concepts. In the future, we may incorporate asynchronous auditory feedback, which has been shown to be highly popular with students and increases perceived teaching presence because it is more effective at preserving nuances, demonstrating faculty interest and involvement, as well as faculty caring [23]. This kind of feedback could easily be situated within our courses.

Formative evaluations suggested that the courses largely met the Quality Matters standards and had successfully implemented EPAID tenets. Student evaluations were largely positive; as we anticipated, group issues were the most serious problem. Students also felt that some courses had too much content. That this was the case in the Border Health course was validated by an external reviewer and that content has been reduced dramatically. Navigation was difficult for a few students. We are currently using the results of the evaluations to refine the courses. Content is being reduced in those courses where it was a problem and navigation issues have been clarified. In addition, we are building in activities throughout that will improve group dynamics (things we would have done automatically in face-to-face group work but forgot in the design of these courses). For example, we have built into the courses group development and evaluation activities. In addition, the challenges in the Technology course have been refined so that each builds on the other more directly. In future iterations, we anticipate moving some aspects of the courses into Second Life, which should allow us to create an even richer environment for learning. At the time we developed the courses, Second Life was totally text-based and the University did not own an island for education. These constraints no longer exist, so we are moving rapidly to explore this environment.

\section{REFERENCES}

1. Gibson, E. J. Principles of Perceptual Learning and Development. New York: Appleton-Century Croft, 1969.

2. Gibson, J. J. The Ecological Approach to Visual Perception. Hillsdale, NJ: Lawrence Erlbaum Associates, Inc., 1986 (Original work published 1979).

3. Mace, W. M. James J. Gibson's Strategy for Perceiving: Ask Not What's Inside Your Head, But What Your Head’s Inside Of. In R. E. Shaw \& J. Bransford (Eds), Perceiving, Acting, and Knowing. Hillsdale, N.J.: Lawrence Erlbaum Associates, 1977.

4. Young, M. An Ecological Psychology of Instructional Design: Learning and Thinking by PerceivingActing Systems. In D. H. Jonassen (Ed.), Handbook of Research on Educational Communications and Technology, 2nd ed., 169-177. Mahwah, NJ: Erlbaum, 2004.

5. Gibson, E. J. Perceptual Learning in Development. Ecological Psychology 12: 295-302, 2000.

6. Gibson, E. J. Principles of Perceptual Learning and Development. New York: Appleton-Century Croft, 1969.

7. Merleau-Ponty, M. Phenomenology of Perception. Colin Smith (translator). New York: Humanities Press, 1962.

8. Effken, J. A. and Kadar, E. E. Learning as Progressive Biasing of a Random Walk Process: Toward an Ecological Theory of Exploratory Learning. Ecological Psychology 13: 1-30, 2001.

9. Shaw, R. E., Kadar, E., Sim, M. and Repperger, D. W. The Intentional Spring: A Strategy for Modeling Systems that Learn to Perform Intentional Acts. Journal of Motor Behavior 24: 3-28, 1992. 
Application and Evaluation of the Ecological Psychology Approach to Instructional Design (EPAID)

10. Young, M. F., Barab, S. and Garrett, S. Agent as Detector: An Ecological Psychology Perspective on Learning by Perceiving-acting Systems. In D. H. Jonassen \& S. M. Land (Eds.), Theoretical Foundations of Learning Environments, 147-172. Mahwah, NJ: Erlbaum, 2000.

11. Cognition and Technology Group at Vanderbilt. Anchored Instruction and its Relationship to Situated Cognition. Educational Researcher 19(6): 2-10, 1990.

12. Cognition and Technology Group at Vanderbilt (1993). Anchored Instruction and Situated Cognition Revisited. Educational Technology 33 (3): 52-70, 1993.

13. Hannafin, M. J. Emerging Technologies, ISD, and Learning Environments: Critical Perspectives. Educational Technology Research and Development 40(1): 49-63, 1992.

14. Kulkowich, J. M. and Young, M. F. Locating an Ecological Psychology Methodology for Situated Action. Journal of the Learning Sciences 10(1\&2): 165-202, 2001.

15. Young, M. F., DePalma, A. and Garrett, S. Situations, Interaction, Process and Affordances: An Ecological Psychology Perspective. Instructional Science 30: 47-63, 2002.

16. Shaw, R. E., Effken, J. A., Fajen, B. R., Garrett, S. R. and Morris, A. An Ecological Qpproach to the On-line Assessment of Problem-solving Paths: Principles and Applications. Instructional Science 25(2): 151-166, 1997.

17. Anzaldúa, G. To Live in the Borderlands Means You .... In T. Miller (Ed.), Writing on the Edge: A Borderlands Reader, 91-92. Tucson, AZ: The University of Arizona Press, 2003.

18. Leasure, A. R., Davis, L. and Thievon, S. Comparison of student outcomes and preferences in a traditional vs. world wide web-based baccalaureate nursing research course. Journal of Nursing Education 39(4): 149-54, 2000.

19. Ryan, M., Carlton, K. H. and Ali, N. S. Evaluation of traditional classroom teaching methods versus course delivery via world wide web. Journal of Nursing Education 38(6): 272-77, 1999.

20. Halstead, J. A. and Coudret, N. A. Implementing Web-based Instruction in a School of Nursing: Implications for Faculty and Students. Journal of Professional Nursing 15(5): 273-281, 2000.

21. Sener, J. Quality Matters: Inter-institutional quality improvement for online courses. Journal of Asynchronous Learning Networks 10(1): February, 2006.

22. Garrison, D. R. Online Communities of Inquiry Review: Social, Cognitive, and Teaching Presence. Journal of Asynchronous Learning Networks 11(1): Apr, 2007.

23. Ice, P., Curtis, R., Phillips, P., and Wells, J. Using Asynchronous Audio Feedback to Enhance Teaching Presence and Students' Sense of Community. Journal of Asynchronous Learning Networks 11(2): July, 2007.

\section{ACKNOWLEDGEMENTS}

This work was sponsored by HRSA Grant 1 D09HP03116-01-00. The authors would like to thank Drs. Joyce Verran and Gerri Lamb, who helped with the original course designs, Drs. Patricia Flatley Brennan and Diane Skiba, who served as consultants on the project, and Zu-Chun Lin and Rudy Valenzuela, who were graduate teaching associates for the project. In addition, we owe a huge debt of gratitude to Bruce Cameron, Instructional Designer and the TRIAD instructional technology team at The University of

Arizona. Portions of this paper were presented at the Sloan-C International Symposium: Emerging Technology Applications for Online Learning, May 7-9, 2008 in Carefree, AZ.

\section{ABOUT THE AUTHORS}

Judith Effken is a Professor at The University of Arizona College of Nursing in Tucson, AZ.

Marylyn McEwen is an Associate Professor at The University of Arizona College of Nursing in Tucson, AZ. 
Deborah Vincent is an Associate Professor at The University of Arizona College of Nursing in Tucson, AZ.

Kimberly Shea is now an Assistant Professor at the Arizona State University College of Nursing in Phoenix, AZ. When this work was done, she was a graduate teaching associate at The University of Arizona.

Dianna Garcia-Smith is now an Assistant Professor at the School of Nursing of The University of Texas-Brownsville, in Brownsville, TX. When this work was done, she was a graduate teaching associate at The University of Arizona.

Youngmi Kang is now an Assistant Professor at the Carolyn McKelvey Moore School of Nursing of The University of Arkansas-Fort Smith, in Fort Smith, AR. When this work was done, she was a graduate teaching associate at The University of Arizona.

Michael Young is an Associate Professor in the Department of Educational Psychology at the University of Connecticut, Storrs, CT. 